\title{
NOTA
}

\section{EFEZIËRS 1,7-10 IN DE NIEUWE BIJBELVERTALING}

\author{
Jan Lambrecht ${ }^{1}$
}

De zogeheten lofzang van de brief aan de Efeziërs, 1,3-14, bestaat uit één lange zin, de langste van het Nieuwe Testament, in een overdadige en overladen stijl. God wordt er geprezen, omdat hij ons in en door Christus met allerhande geestelijke zegeningen gezegend heeft (v. 3), ons uitverkozen heeft om een heilig leven te leiden en ons door Jezus Christus voorbestemd heeft tot kindschap. Dit moet strekken tot lof van zijn heerlijke genade, waarmee hij ons in de geliefde Christus begenadigd heeft (vv. 4-6). Door Jezus' bloed hebben we de verlossing ontvangen, de vergiffenis van onze zonden, en dit dank zij de rijkdom aan genade die God ons overvloedig in alle wijsheid heeft geschonken. Dit blijkt daaruit dat hij ons het geheim van zijn wil bekend gemaakt heeft om in Christus alles in hemel en op aarde onder één hoofd te brengen (vv. 7-10). In Christus zijn wij, die als vroegere joden reeds lang op hem hadden gewacht, erfgenamen geworden. Maar ook gij, christenen uit het heidendom, werdt verzegeld met de beloofde heilige Geest, die het onderpand is van onze erfenis, dit alles tot verlossing van zijn verworven bezit, tot lof van zijn heerlijkheid (vv. 11-14).

In deze lofzang valt op dat Gods uitverkiezing in Christus plaatsheeft "voor de grondlegging van de wereld" (v. 4); dit geldt ook voor de voorbestemming (v. 5). God heeft dus met de preëxistente Christus van alle eeuwigheid in de hemel gepland en beslist wat op aarde in de tijd geschied is en nog zal geschieden.

In 1,3-14 volgen drie lange bijzinnen op elkaar, de verzen 7-10, 11-12 en 13-14, elk beginnend met év $\hat{\varphi}$ ("in wie"). Dit betrekkelijk voornaamwoord heeft ook iedere keer "Christus" als antecedent, in vers 6 in de vorm van "de geliefde". Deze korte bijdrage beperkt zich

1 Prof. Jan Lambrecht, Waversebaan 220, B-3001 Heverlee (Leuven). Em. prof. KU Leuven, België. E-pos: jan.lambrecht@theo.kuleuven.be. 
tot de eerste bijzin, 1,7-10. Aan het nu volgende onderzoek van de inhoud gaat een summiere vergelijking vooraf van twee recente vertalingen, de herziene Willibrordvertaling $(=W V, 1995)$ en De Nieuwe Bijbelvertaling ( = NBV, 2004).

\section{VERGELIJKING}

\begin{tabular}{|c|c|c|c|}
\hline \multicolumn{2}{|c|}{ De Willibrordvertaling } & \multicolumn{2}{|c|}{ De Nieuwe Bijbelvertaling } \\
\hline $7 \mathrm{a}$ & $\begin{array}{l}\text { In hem hebben wij de } \\
\text { verlossing door zijn bloed, }\end{array}$ & $7 \mathrm{a}$ & $\begin{array}{l}\text { In hem zijn we door zijn bloed } \\
\text { verlost }\end{array}$ \\
\hline $\mathrm{b}$ & de vergeving van de zonden, & $\mathrm{b}$ & en zijn onze zonden vergeven, \\
\hline c & dankzij zijn rijke genade. & c & dankzij de rijke genade \\
\hline $8 \mathrm{a}$ & Daarmee heeft hij ons overladen & $8 \mathrm{a}$ & $\begin{array}{l}\text { die hij ons in overvloed heeft } \\
\text { geschonken. }\end{array}$ \\
\hline $\mathrm{b}$ & in al zijn wijsheid en inzicht. & $\mathrm{b}$ & $\begin{array}{l}\text { Hij heeft ons in al zijn wijsheid } \\
\text { en inzicht }\end{array}$ \\
\hline $9 \mathrm{a}$ & $\begin{array}{l}\text { Want hij heeft ons het geheim } \\
\text { van zijn wil bekend gemaakt, }\end{array}$ & $9-10 \mathrm{a}$ & $\begin{array}{l}\text { dit mysterie onthuld: zijn } \\
\text { voornemen om met Christus de } \\
\text { voltooiing van de tijd te verwe- } \\
\text { zenlijken en zijn besluit }\end{array}$ \\
\hline $\mathrm{b}$ & overeenkomstig het besluit & & \\
\hline c & dat hij in Christus had genomen, & & \\
\hline $10 \mathrm{a}$ & $\begin{array}{l}\text { ter verwezenlijkig van de } \\
\text { volheid van de tijden: }\end{array}$ & & \\
\hline $\mathrm{b}$ & $\begin{array}{l}\text { alles in Christus onder één } \\
\text { hoofd samen te brengen, }\end{array}$ & $10 \mathrm{bc}$ & $\begin{array}{l}\text { om alles in de hemel en op } \\
\text { aarde onder één hoofd bijeen te } \\
\text { brengen, onder Christus. }\end{array}$ \\
\hline & $\begin{array}{l}\text { alles in de hemelse regionen } \\
\text { en alles op aarde, in hem. }\end{array}$ & & \\
\hline
\end{tabular}

$N B V$ vertaalt vers $7 \mathrm{~b}$ met een persoonlijke constructie en laat $8 \mathrm{a}$ aansluiten bij 7c, om in $8 \mathrm{~b}$ een nieuwe zin te beginnen die doorloopt tot het eind van vers 10 . De $W V$ begint zowel $8 \mathrm{a}$ als 9a met een nieuwe zin. Buiten haar toevoeging van "want" in 9a, volgt haar weergave van de verzen 9-10 van dichtbij de Griekse zinsbouw. Dit is niet geval bij $N B V$. Deze verbindt de verzen 9 en 10 tot een eenheid en identificeert "het mysterie van Gods wil" met (1) "zijn voornemen" en (2) "zijn besluit", waarop dan telkens een completieve bepaling met "om" volgt: (1) "om met Christus de voltooiing van de tijd te verwezenlijken" en (2) "om alles in de hemel en op aarde onder één hoofd bijeen te brengen, onder Christus". Ook WV heeft in 10b "onder één hoofd". Terecht? 
De verdere bespreking gaat na in hoeverre de $N B V$ trouw blijft aan de grondtekst. Een letterlijke vertaling zal daarbij behulpzaam zijn.

\section{DE VERZEN 7-8}

7a in wie wij de verlossing hebben door zijn bloed,

b de vergiffenis van de zonden,

c overeenkomstig de rijkdom van zijn genade,

8a die hij ons overvloedig geschonken heeft

b in alle wijsheid en inzicht.

De NBV geeft vers 7 nogal omschrijvend weer: "in hem zijn we door zijn bloed verlost" (7a), "zijn onze zonden vergeven" (7b), "dankzij de rijke genade" (7c). Volgens de originele tekst bezitten we de verlossing door zijn bloed en is deze niets anders dan de vergeving van de zonden; die verlossing danken we aan de rijkdom van zijn (= Gods) genade. Door de omschrijvingen in $N B V$ dreigen de door de schrijver bedoelde schakeringen te vervagen.

De adverbiale bepaling "in overvloed" $(8 \mathrm{a} ; N B V)$ is er wellicht de medeoorzaak van dat $N B V$ "in al zijn wijsheid en inzicht" (8b) niet als tweede bepaling bij "heeft geschonken" leest, maar bij "heeft onthuld" voegt (9a). De meeste commentatoren merken op dat nergens in de brief een zin met een bijwoordelijke bepaling begint, terwijl dat volgens $N B V$ hier toch zou gebeuren: "in al zijn wijsheid en inzicht heeft hij ons...". Het onderwerp van $\pi \epsilon \rho \iota \sigma \sigma \epsilon ́ v \omega$ (hier letterlijk: "doen overvloeien") is God. In een voetnoot legt de WV uit dat "in alle wijsheid en inzicht" ook zou kunnen slaan op de gelovigen: God heeft hen verrijkt met alle wijsheid en inzicht. Maar het gaat in vers $8 \mathrm{~b}$ hoogstwaarschijnlijk toch over Gods wijsheid en inzicht.

\section{DE VERZEN 9-10}

9a door het geheim van zijn wil bekend te maken,

b overeenkomstig zijn besluit,

c dat hij in hem had genomen

10a tot de verwezenlijking van de volheid van de tijden,

b (namelijk) alles samen te brengen in Christus,

c al wat in de hemelen en op de aarde is, in hem, 
Doordat 9c en 10a samen een betrekkelijke zin vormen die "zijn besluit" bepaalt, legt pas vers $10 \mathrm{bc}$ de bekendmaking van het geheim uit en verklaart het nader waarin Gods wil bestaat. "Besluit" is de

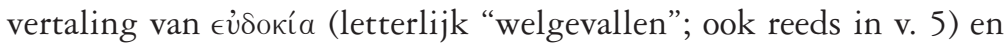
"door ... bekend te maken" (9a) die van het deelwoord $\gamma v \omega$ píaas. Dit deelwoord bezit wellicht een redengevende nuance door $W V$ geëxpliciteerd met "want". God deelt ons in al zijn wijsheid en inzicht zijn overvloedige gave van genade mee (v. 8); die gave houdt blijkbaar een bekendmaking in. Ze heeft plaats in de tijd, terwijl "het geheim van zijn wil" (9a) reeds bestond voor de grondlegging van de wereld, dus vóór de tijd (vgl. v. 4). Ook Gods "samenbrengen in Christus" gebeurt in de tijd. Maar dit samenbrengen is t.o.v. de bekendmaking van zijn verborgen wil iets nog toekomstigs. God heeft zijn verborgen wil om alles samen te brengen bekend gemaakt. Het werkwoord

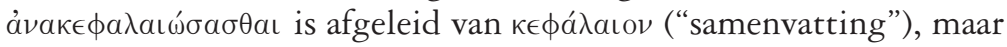

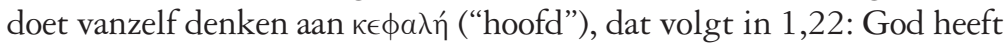
Christus aan de kerk gegeven als hoofd boven alles (zie ook 4,14 en 5,23). De vertaling "onder één hoofd samenbrengen (of bijeenbrengen)" van het werkwoord in $10 \mathrm{~b}$ door $W V$ en $N B V$ is dus niet totaal uitgesloten. Maar "in Christus" (10b) en "in hem" (10c) maken deze vertaling minder waarschijnlijk. Men moet hier bovendien rekening houden met de inhoud van vers 7 , dat tot dezelfde $\hat{e} v \hat{\dot{\omega}}$-zin behoort: "de verlossing door zijn bloed" en "de vergeving van de zonden". Daardoor brengt God inderdaad alles in de hemel en op de aarde in Christus onder één hoofd (?) samen (10bc).

De betrekkelijke zin van 9c-10a legt uit dat God in hem (= Christus) zijn besluit genomen had met het oog op de verwezenlijking van de volheid der tijden ( en de voorbestemming dateert ook die beslissing van voor de grondlegging van de wereld. Gods uiteindelijke doel, dat blijkbaar bestaat in het samenbrengen van alles in Christus, valt samen met de bewerkstelliging van de volheid van de tijden, d.i. de voltooiing van de geschiedenis. Gods welwillende besluit werd genomen in de hemel, vóór de tijd, maar de uitvoering ervan heeft plaats op aarde, binnen de tijd. Volgens de schrijver van Efeziërs is de heilsgeschiedenis nog volop bezig. De voltooiing ervan is nog toekomst. 
NBV heeft de verzen 9-10 te vrij en bovendien onnauwkeurig weergegeven. De nieuwe aanzet begint niet in $8 \mathrm{~b}$, maar met het deelwoord $\gamma \nu \omega i^{\prime \sigma a s}$ in 9a. Waarschijnlijk geeft "zijn voornemen" in NBV de term

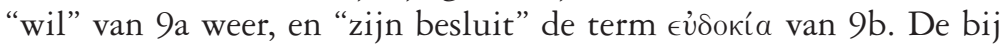

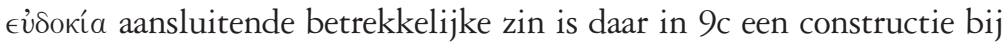
"zijn voornemen" geworden: "om te...", en beantwoordt aan 10a van de grondtekst. NBV laat in het donker dat dit voornemen in Christus genomen is, nog voor de grondlegging van de wereld. Terwijl 10bc in de grondtekst uitlegt waarin "het geheim van zijn (= Gods) wil" bestaat, plaatst $N B V$ "zijn voornemen" en "zijn besluit" grammaticaal en gedachtelijk op dezelfde hoogte; dit doet zij eveneens met de twee constructies met "om":

Hij heeft ons dat mysterie onthuld:

zijn voornemen

om met Christus de voltooiing ... te verwezenlijken

en zijn besluit om alles ... onder één hoofd bijeen te brengen ...

In 10bc verduidelijkt NBV met "onder Christus" "onder één hoofd", maar volgens de grondtekst gebeurt dit samenbrengen "in Christus"; deze wending maakt de toevoeging "onder één hoofd" aanvechtbaar. Het nahinkende "in hem" dat de volgende év $\hat{\dot{\varphi}}$-zin voorbereidt, is door $N B V$ in dat "onder Christus" opgenomen.

\section{BESLUIT}

Men moet erkennen dat het Grieks in 1,7-10 zwaar op de hand is en weinig genietelijk. Maar tevens dat NBV van 1,9-10 een mooie Nederlandse zin gemaakt heeft. Helaas veroorlooft ze zich in de weergave van 1,7-10, de eerste $e^{v} v \hat{\hat{\varphi}}$-zin van de lofzang, te veel vrijheid. Reeds in de verzen 7-8 verwaarloost haar omschrijvende vertaling bepaalde schakeringen van de grondtekst. En in de moeilijke verzen 9-10 getuigt haar weergave niet van voldoende getrouwheid aan de grondtekst. 